\title{
Unit of Angular Acceleration
}

National Cancer Institute

\section{Source}

National Cancer Institute. Unit of Angular Acceleration. NCI Thesaurus. Code C68673.

A unit of the rate of change of angular velocity with respect to time. 